\title{
Paleontology vs. Archaeology in the French Riviera volcanism : crystallized Permian animals and dinosaur skeletons in andesitic rocks, and human remains from the medieval times
}

\section{Florent Pirot}

Independent researcher

\section{ABSTRACT}

This letter details principles of fossilization that matter for the study of fossils in general, but with a preference for sites next to volcanic areas.

${ }^{*}$ Correspondence to Author:

Florent Pirot

Independent researcher

How to cite this article:

Florent Pirot. Paleontology vs. Archaeology in the French Riviera volcanism : crystallized Permian animals and dinosaur skeletons in andesitic rocks, and human remains from the medieval times. International Journal of Archaeological Research, 2021, 2:7.

\section{eScîPub}

eSciPub LLC, Houston, TX USA. Website: https://escipub.com/ 
The fall of dead underwater creatures (clams, ammonites..) in sediments sometimes happens to be only the first step in the fossilization process. The fossilization can continue while the sediments and creatures taken in it get pressed into other layers of rocks after some subduction.

This can happen even opposite to the subduction foss, in the small counter-uplift triggered by subduction, since angles of even 170 degrees for pressure are enough to produce, in a well-water moderated medium, with the sediments bringing organic matter and an initial $0,20 \mathrm{uSv} / \mathrm{h}$ natural radioactivity (on this estimate, see $\left.{ }^{[1]}\right)$ some small nuclear explosions.

The example taken below has been collected north of Entrevaux on the road to the Col de Félines, on the edge just along the small road. The clam was at the margins of such a small nuclear explosion and the interior was molten down but the periphery survived and thanks to the alpha-emitting nanoparticulates and to the bparticles from the fission event, the most resilient parts of the clam's shell where protected by Bose-Einstein condensation [2]. This condensation sublevates slightly these resilient parts.

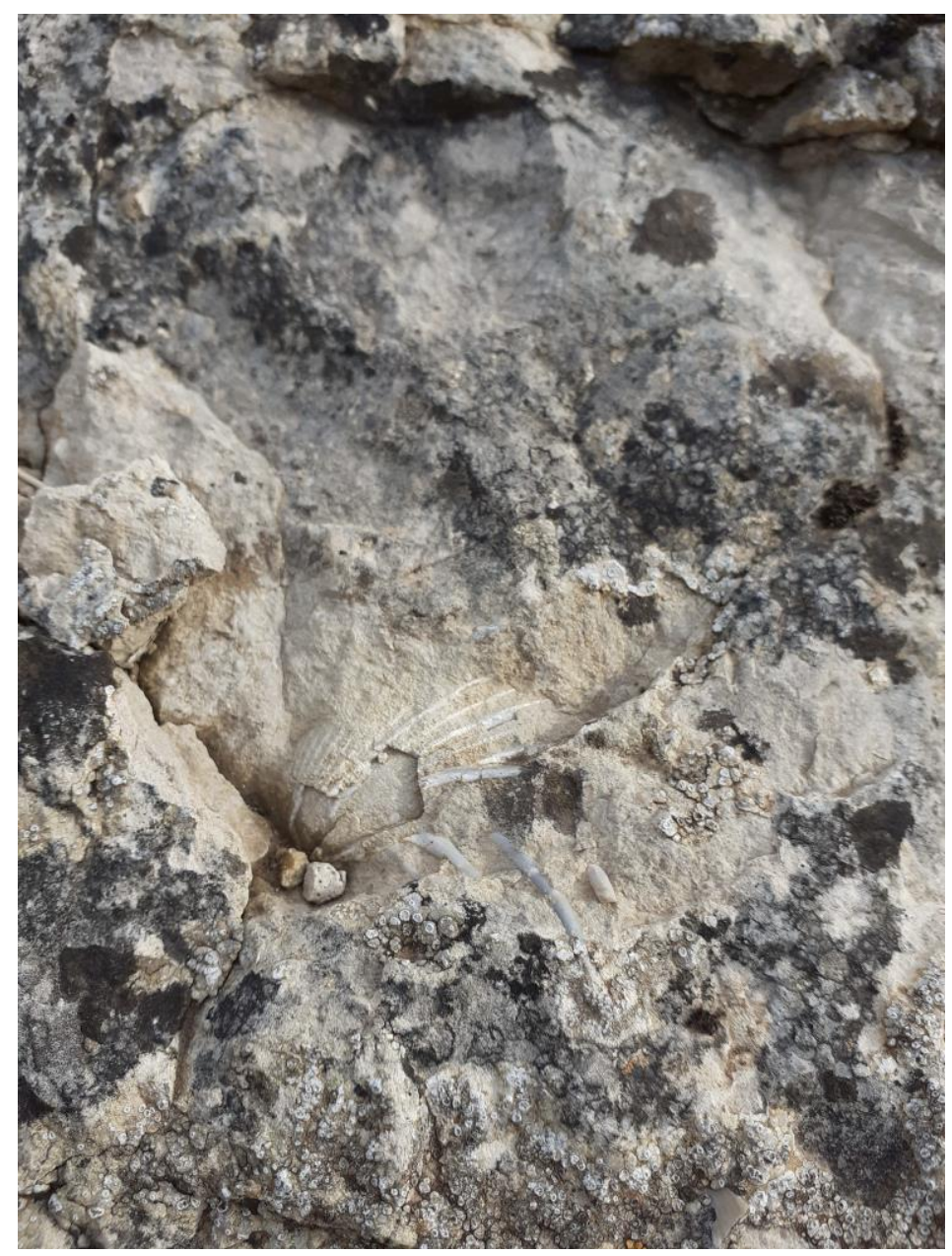

Another example (taken west of the Riolan on a slope) shows a different case with an ammonite taken in the very middle of another small carbonmoderated (from the organic matter dominating in the sediments together with the organic content of the ammonite itself) fission event and dissolved in a fairly homogeneous way but partly crystallized thanks to that and to the pressure brought immediately after by the fall of the soils above it (since the nuclear blast destroys matter pressure comes back afterward). Final erosion of the edges in later times makes it visible to the eye today. 


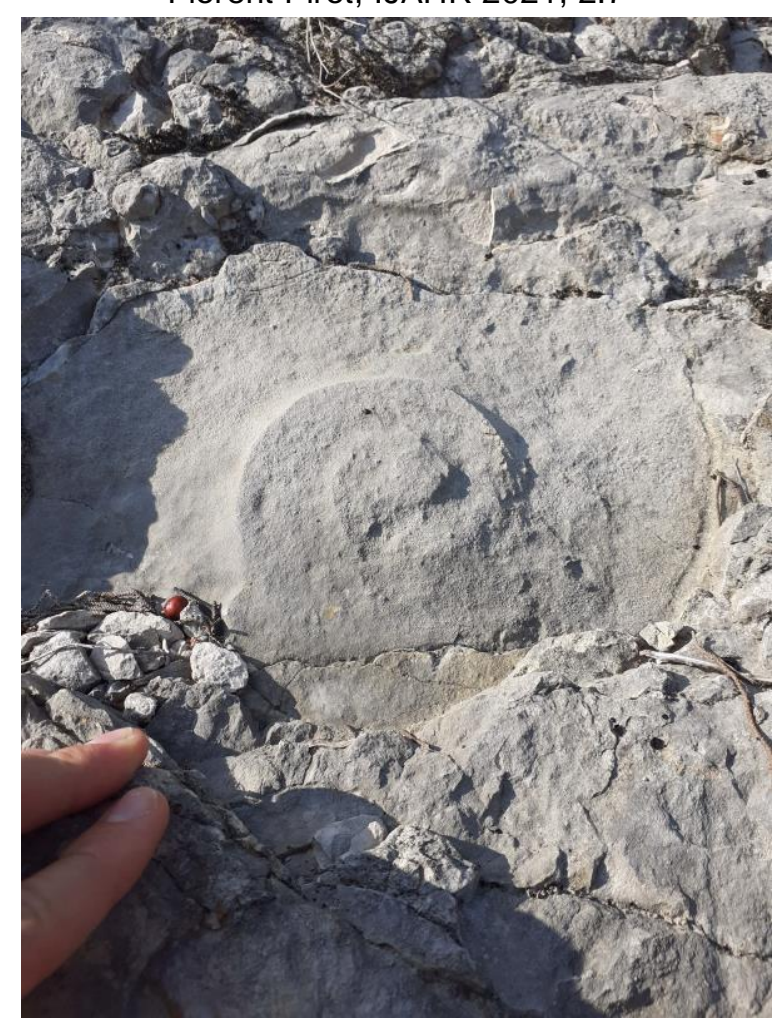

Another case can be shown with smaller rocks found far from alpine volcanism, around SophiaAntipolis, where the mass transfer corresponds to the weights and shows another nuclear explosion cristallizing a clam with less neutron moderation (so deeper in the magmatic chamber, and erupted farther away among small pumice stones).

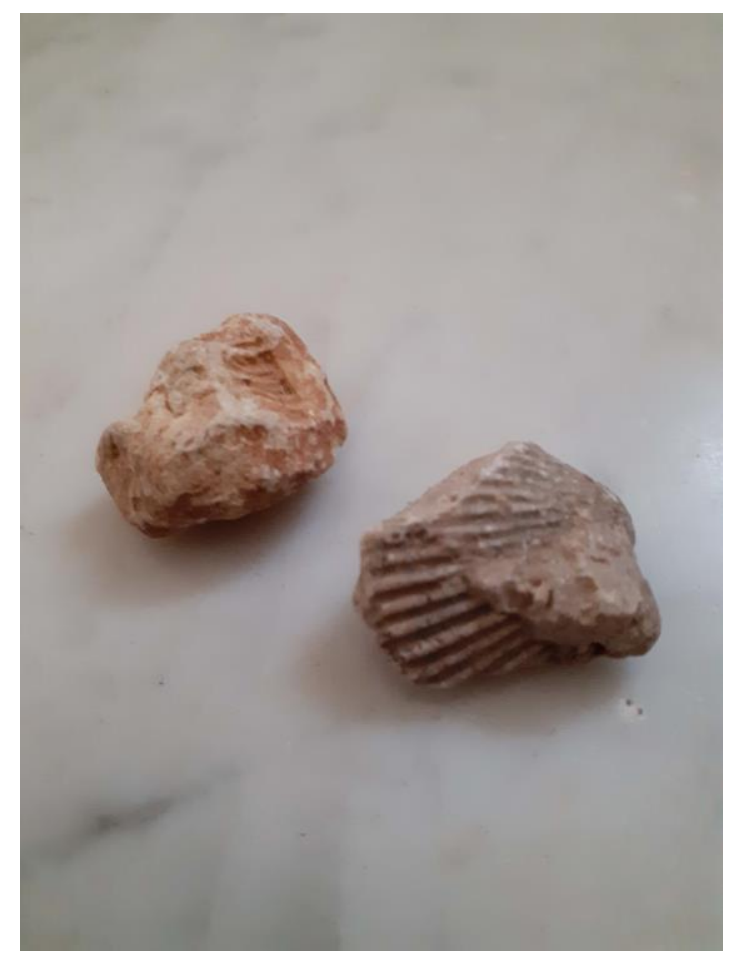

Lastly, it is interesting to show how on a flat shockwave around a shell Bose-Einsteinized the sedimentary area that entered the process, form of the shell (transferred by the shockwave harmonic resonance of the nuclear explosion - see ${ }^{[3]}$ for principle) into a smaller waveform. 


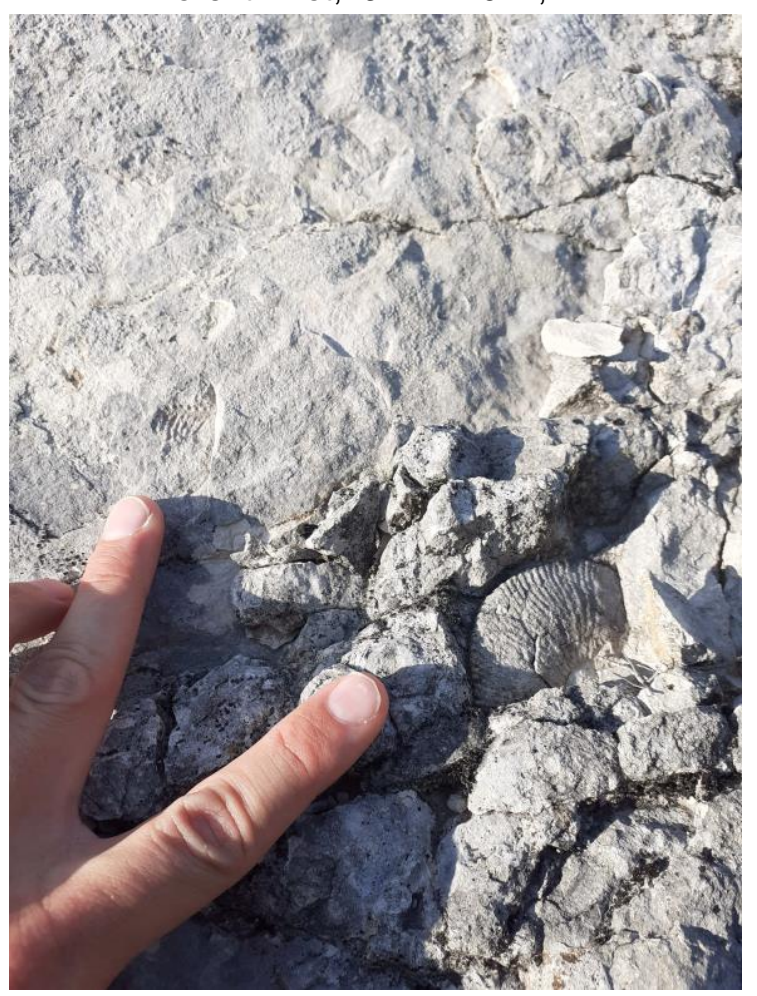

The numerous cases of dinosaur skulls and bodies exposed in this paper together with some cases from the Permian have staggered under the eyes of the wanderers. Water-borne magmatism has allowed the explosive crystallization of bone structures into trails of rocks that have kept the shape of the dinosaurs. Stegosaurus is the most frequently seen dinosaur. The skulls, in particular, have been frequently taken together with other rocks in building processes and are sometimes part of walls, but full dinosaurs can be seen still onto hill flanks.

The natural fossil reserve of Haute-Provence led the author to investigate south-east of that area, along the Alpes Maritimes, where the soils are dominated by the old explosive magmatism of the Alps, with some bottom layers exhibiting Permian remains. The first fossil presented is an excellent Allosaurus head that erupted from a volcano near Le Mas.

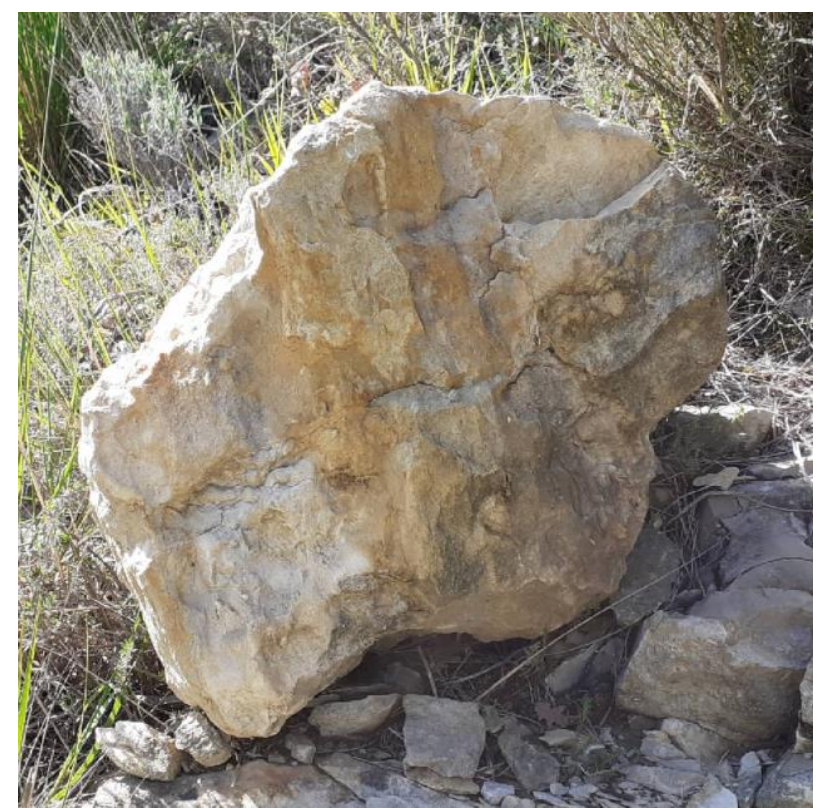


Next to it a Triceratops head also emerges. Two smaller murena-like heads are seen on each side.
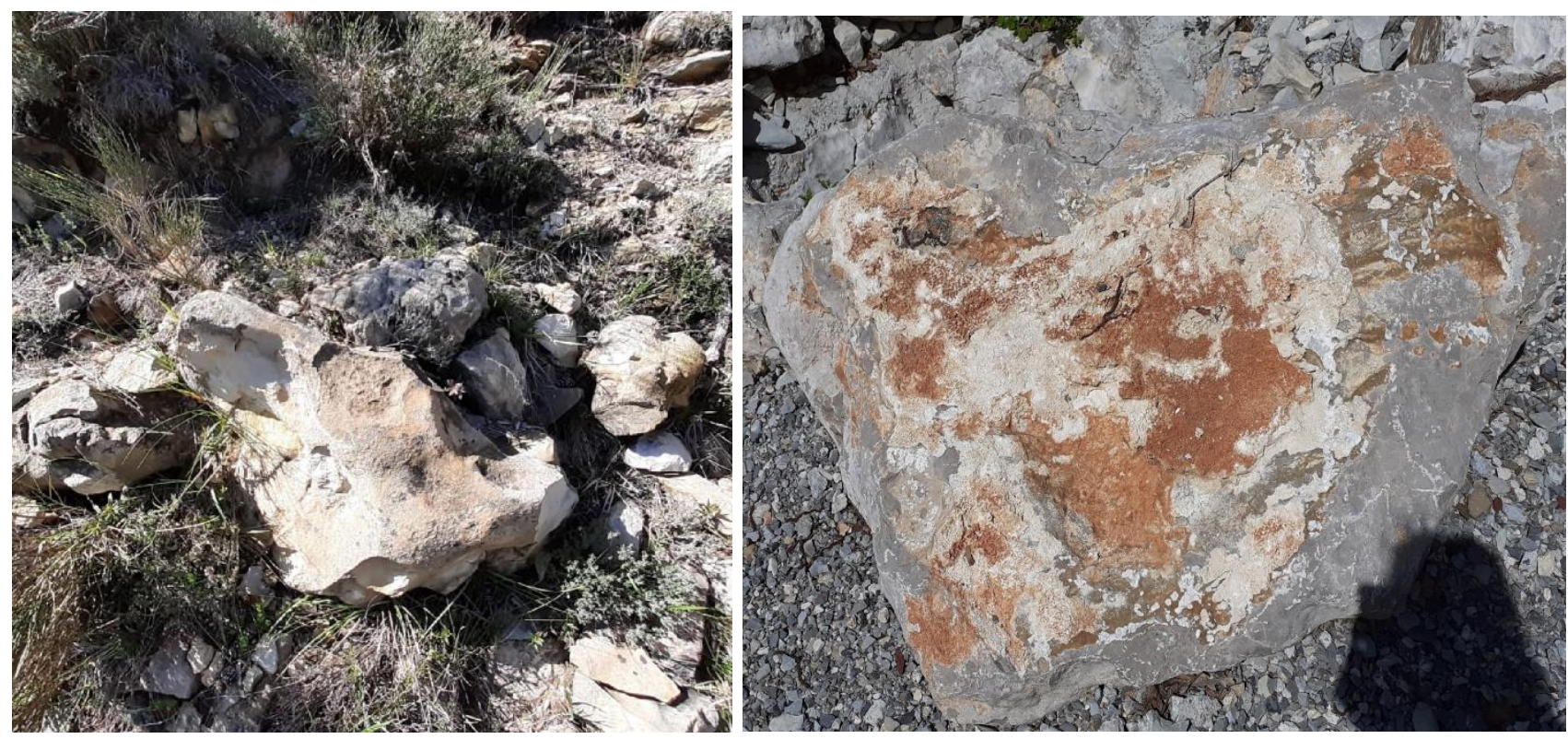

The mouth of the murena on the left is its most

Neutrons from fission are less moderated by visible feature. On the right a longer part of the body of the other murena is also visible. The triceratops certainly died along the seashore on top of a cliff and fell underwater, rolling to the bottom of the trench. Today still near Cannes the depths rapidly reach 1000 meters. As murenas came to feed on the flesh, rocks rolled from above and stumbled upon them, killing them in the act. The subduction process kept the shapes. organic matters and especially by skeletons than by the water spilling from the subduction and actinides from the crust that have surrounded the skeletons benefit from that, fissile actinides from that cast mantle survive slightly more than elsewhere where water was more prominent which is why the resurfaced skeletons have a dim yellow shade with a very soft touch.

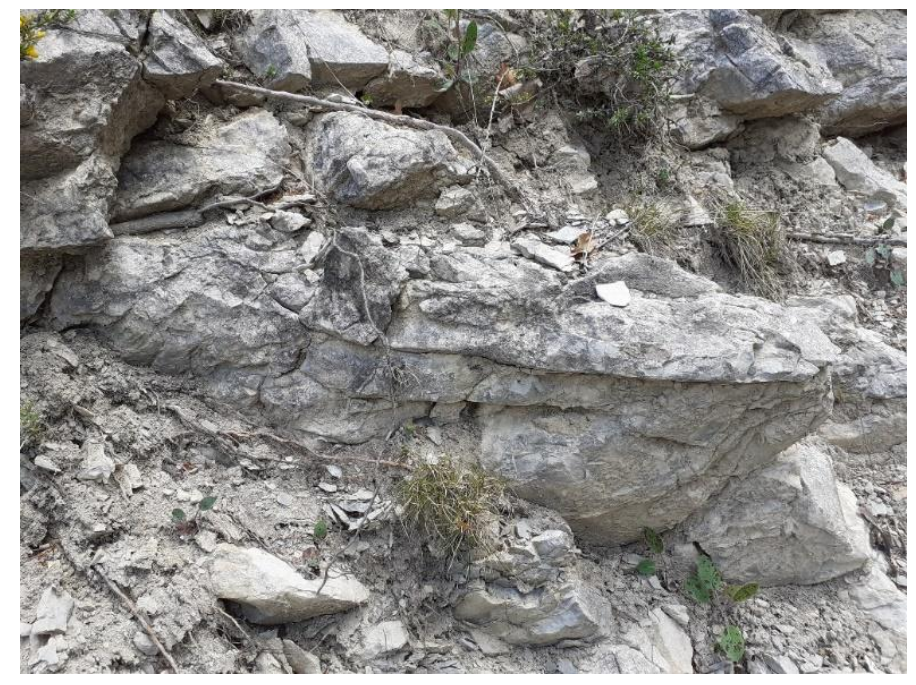

Above, an Estemmenosuchus mirabilis is seen cast into a stone. The stone was found in L'Hubac near Val de Chalvagne and is at a low altitude. The Permian domain in this sector, in the bottom layers, shows also for instance the 
head of a primitive saurischian and more estemmenosuchus heads.
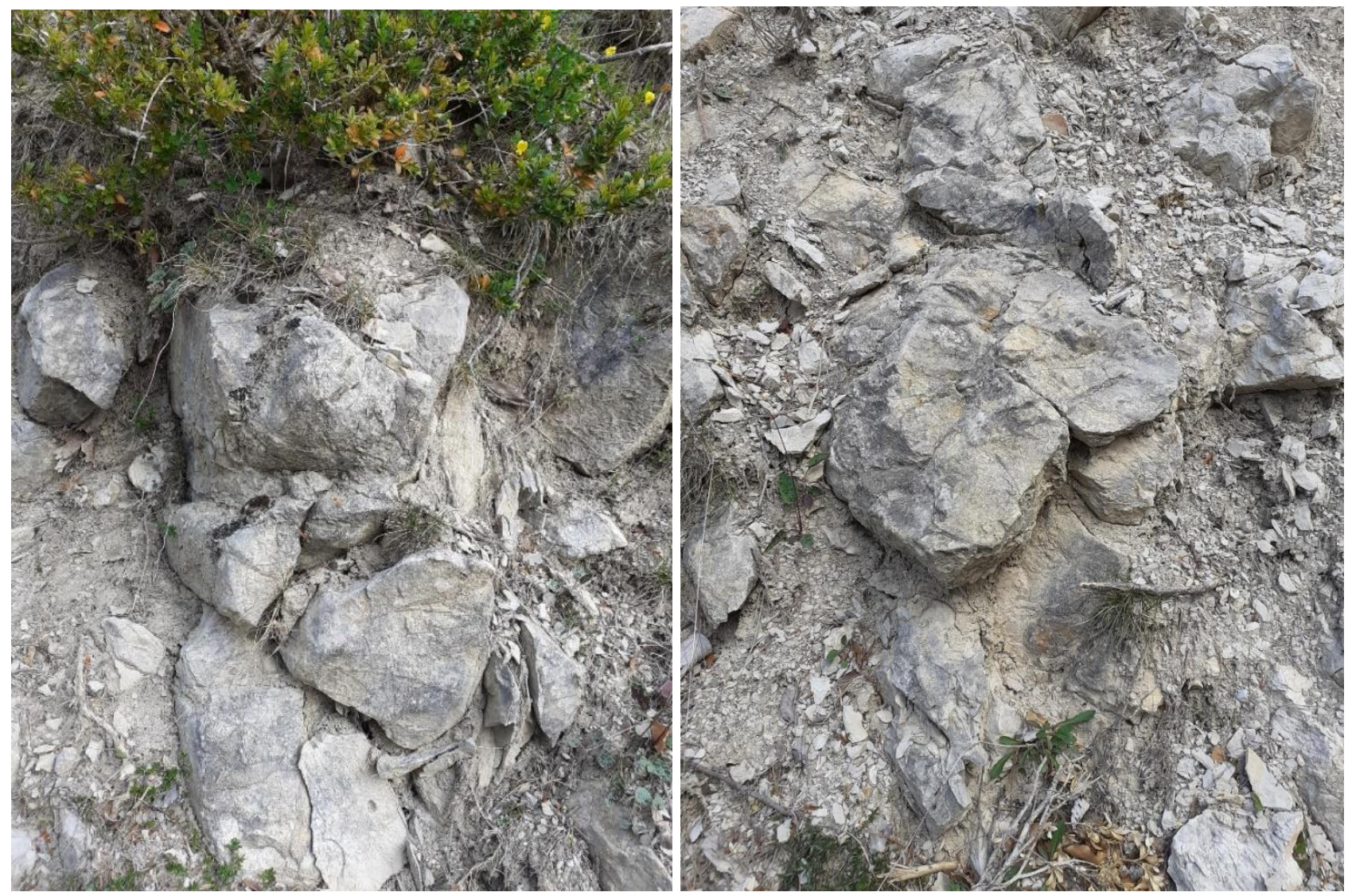

Stegosaurus is the most frequently seen cranial part (indecisive) was also found cast onto dinosaur. At a higher altitude in the Val de a stone next to a soil shape that presents the Chalvagne area, a Stegosaurus caudal or curvature of a stegosaurus.

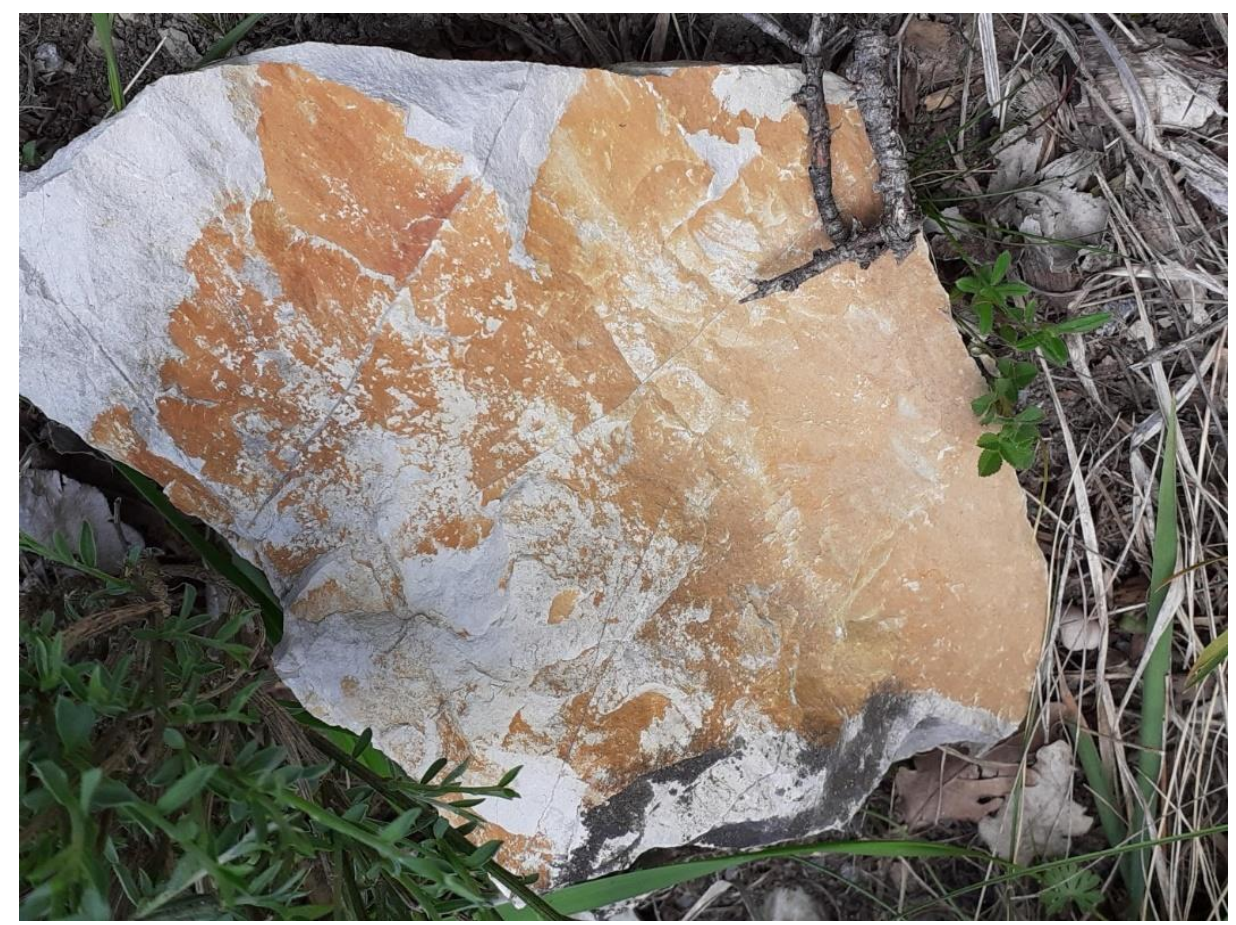


Another stegosaurus was found emerged from a magmatic area in Valbonne, on a walking trail. It is presented next to a typical stegosaurus shape.

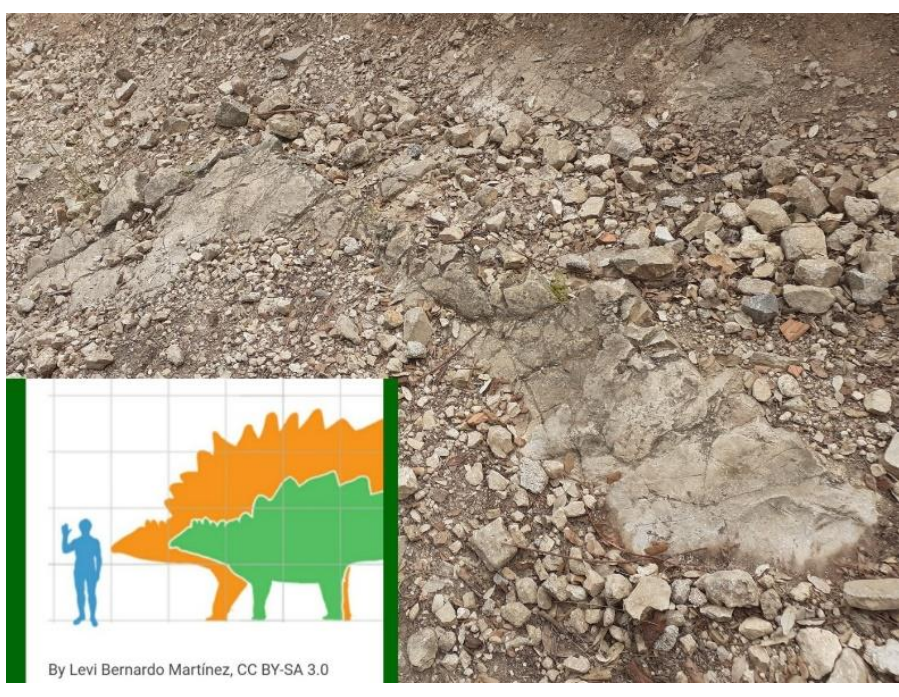

Another stegosaurus was found emerging next to the above one, on the same walking path where, just down under, crocodilians also slowly emerge from the soils.

This individual is the most significant, the Brachychampsa genus of alligatoroids is suggested because of the appearance of plates behind the head. This area underwent phreatomagmatic eruptions and in these cases where entire animals are found fossilized but not strongly crystallized lateral pyroclastic flows are suggested to have culled the animals, falling down onto a layer of pumice and tephra which molded their bodies and even kept some colours.

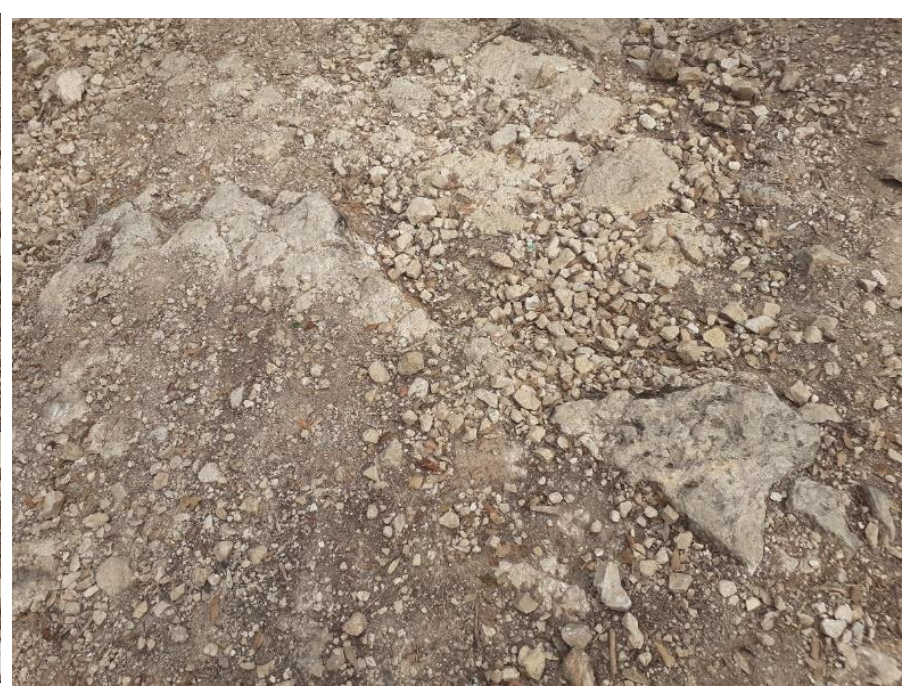

The animals are laid down where they lived, unlike the other cases where the dead bodies fell into trenches and entered subduction, crystallized through the nuclear fission, fission products and basalt taking the mold, before eruptive scattering. Only the head and front of the body of the animal have survived because the pyroclastic flow came from the rear (which is above the head - the Brachychampsa is looking down the slope).

Many more dinosaur skulls have been evidenced in particular in walls where they were recycled among random stones, also around Valbonne.

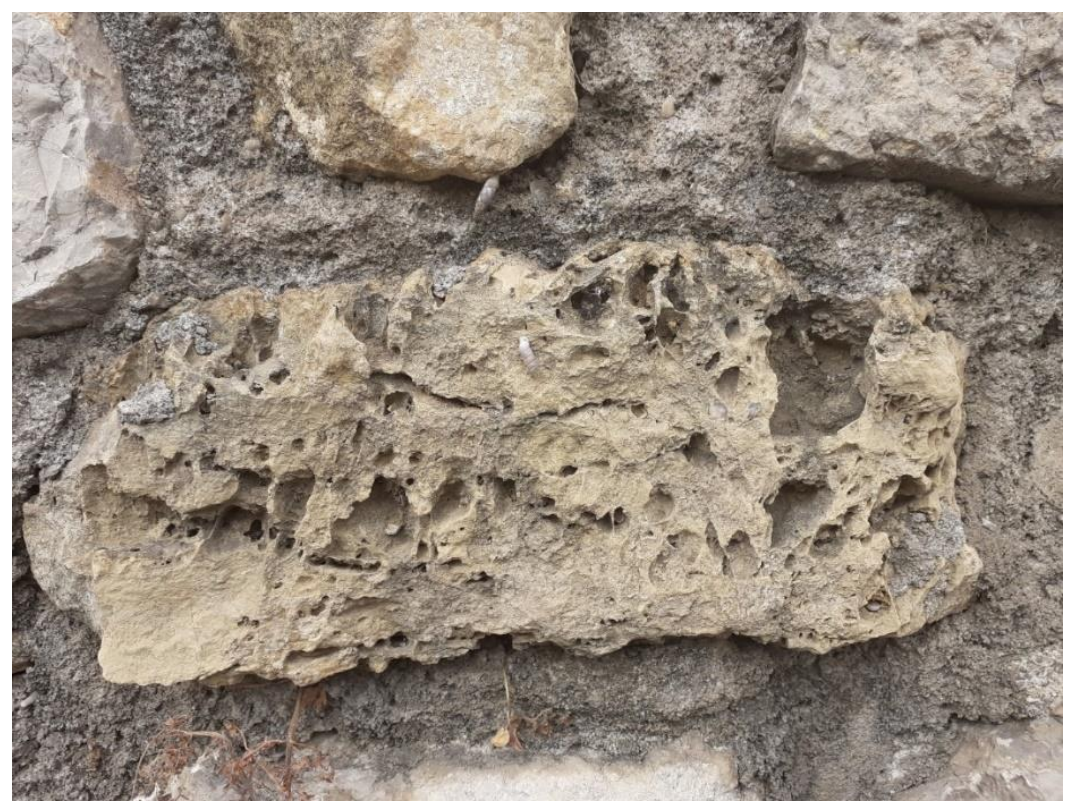


Florent Pirot, IJAHR 2021, 2:7

Below for instance a postosuchus-like crocodilian.

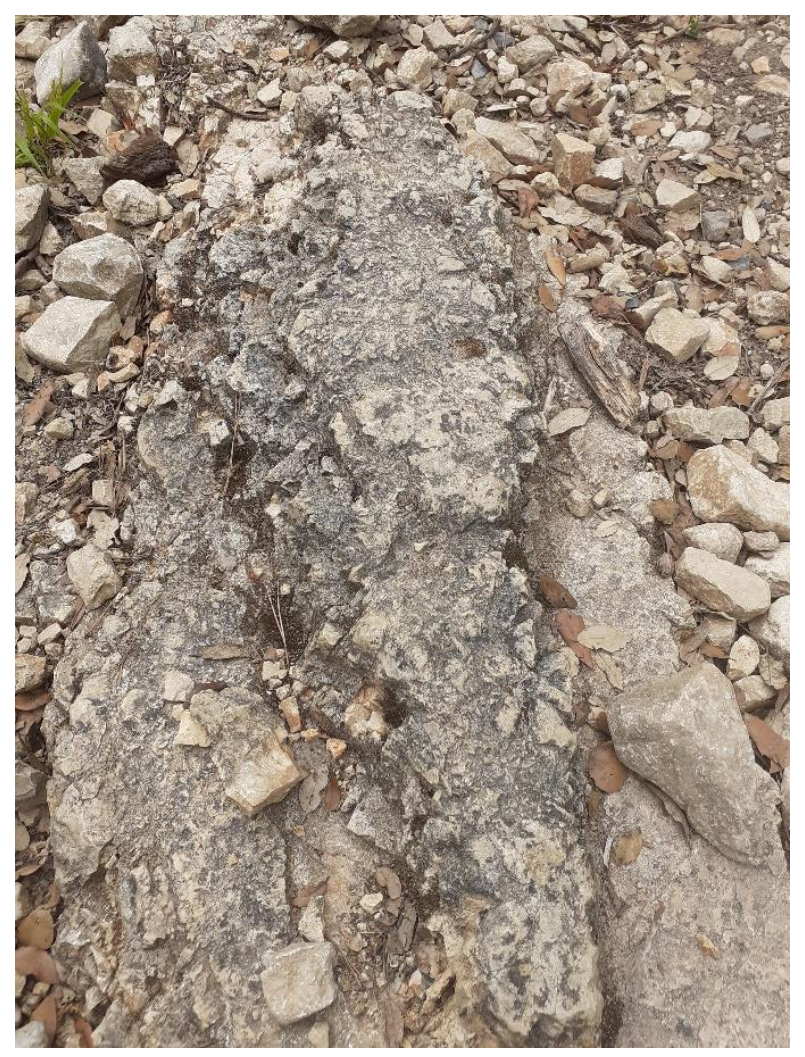

Next, possibly a small tyrannosaurus skull, and an allosaurus skull.
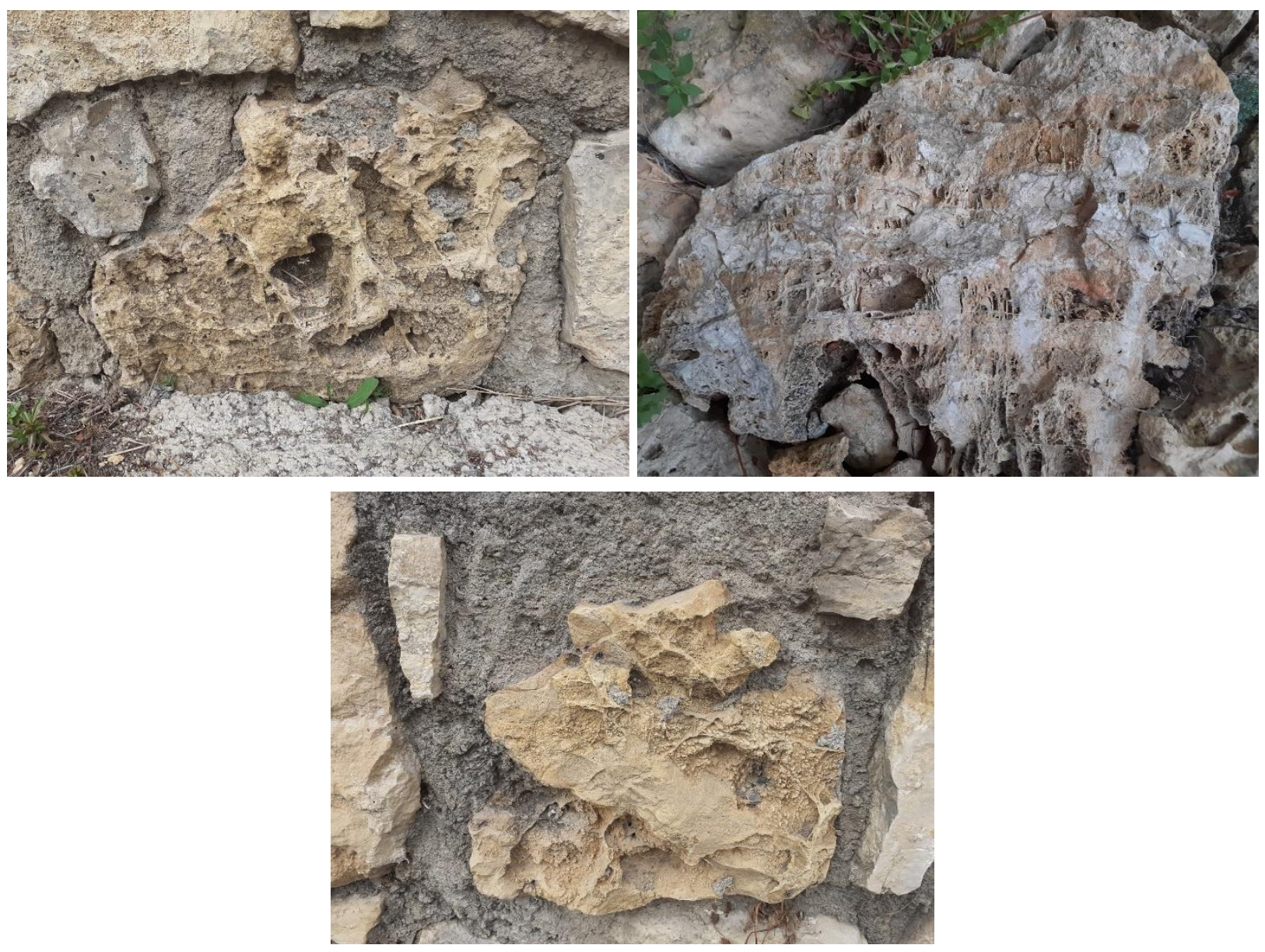
Pachycephalosaurus - the most advanced teeth were separated by the explosion. Several skulls in

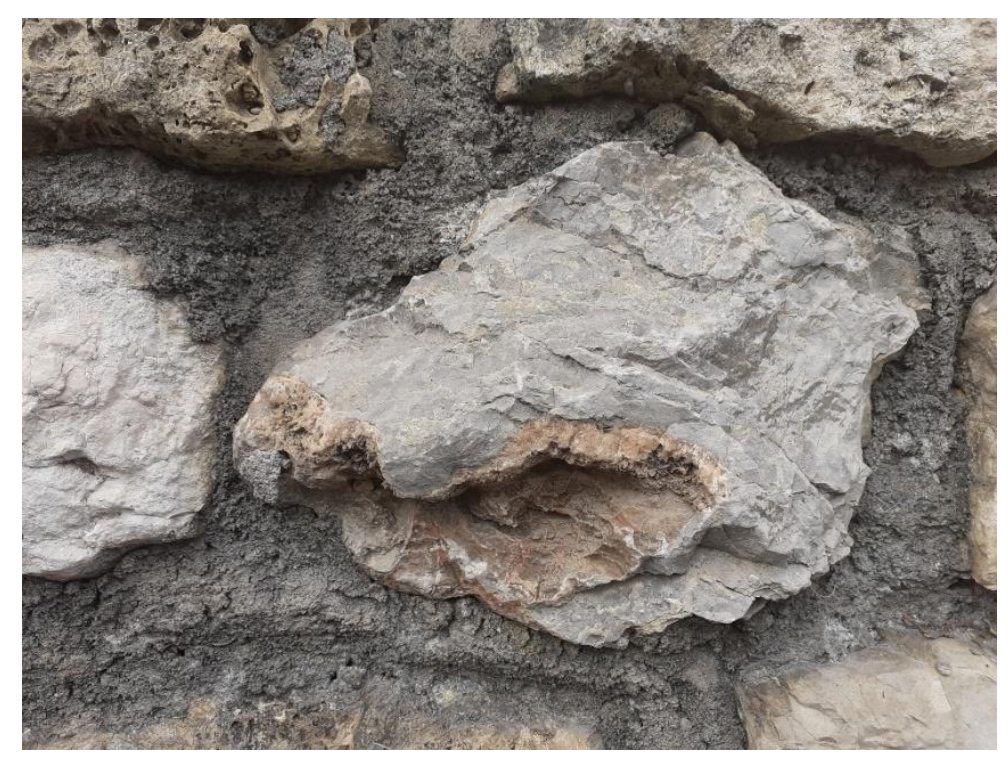

the same area might be phases from the same skull, the volcanism was less active in these hills of low altitude and the long time between eruptions allowed the phases to separate before small eruptions put out the prints of the dead dinosaur out. The water-moderated nuclear explosions produce very asymmetrical fission products and in this case is blatant with the smaller bulged teeth part separated by the event.
Another pachycephalosaurus is quite well preserved as a kind of quasi-pumice material. An edited full skull is presented along for comparison (credits to user Ballista from Wikipedia who scooped a Pachycephalosaurus wyomingensis in the Oxford University Museum of Natural History).
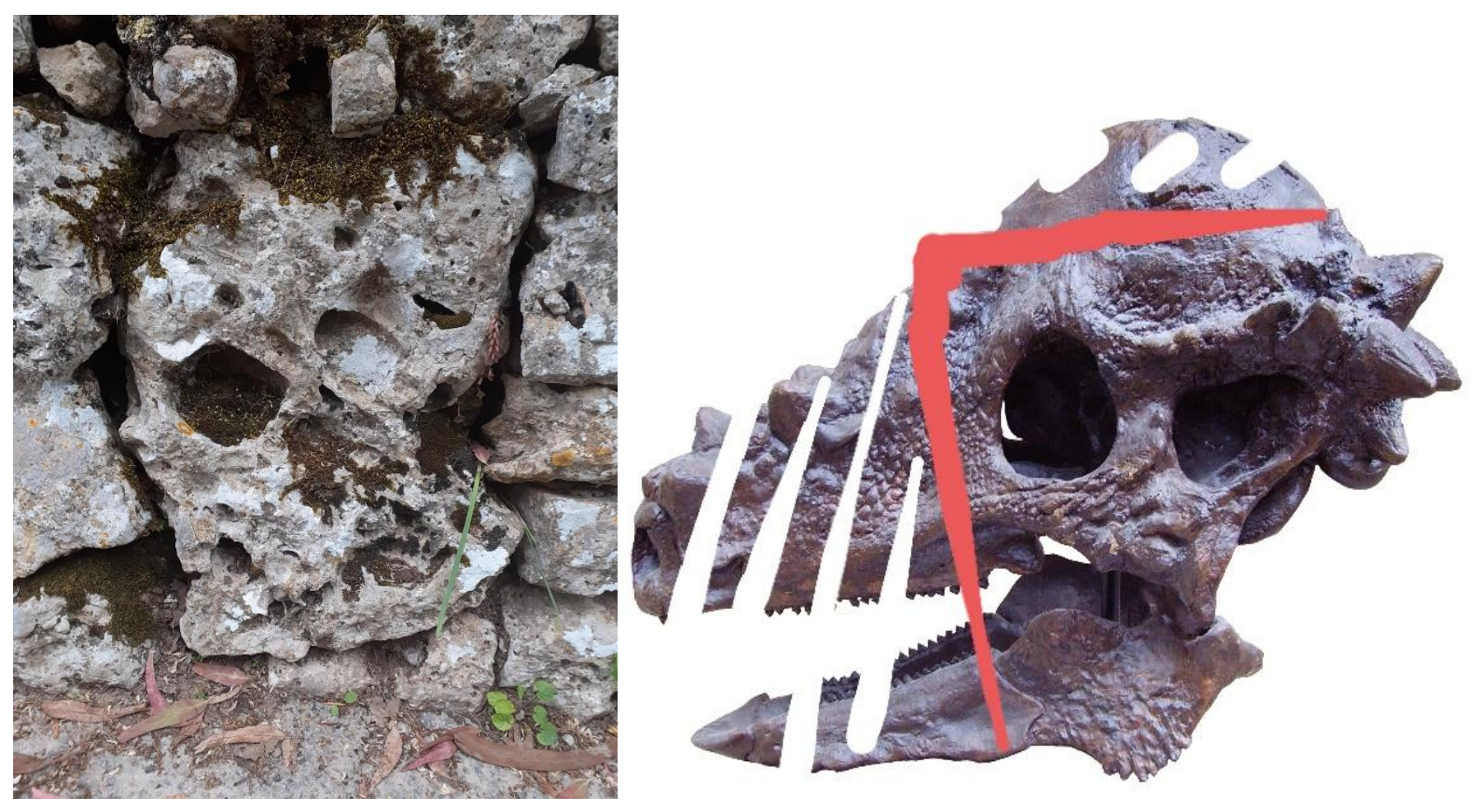
In St Auban in a riverbed another stegosaurus kind of fossilization. A baby stegosaurus was and its excellently preserved head was visible also visible behind. Below the head: emerging in a way that suggests a traditional

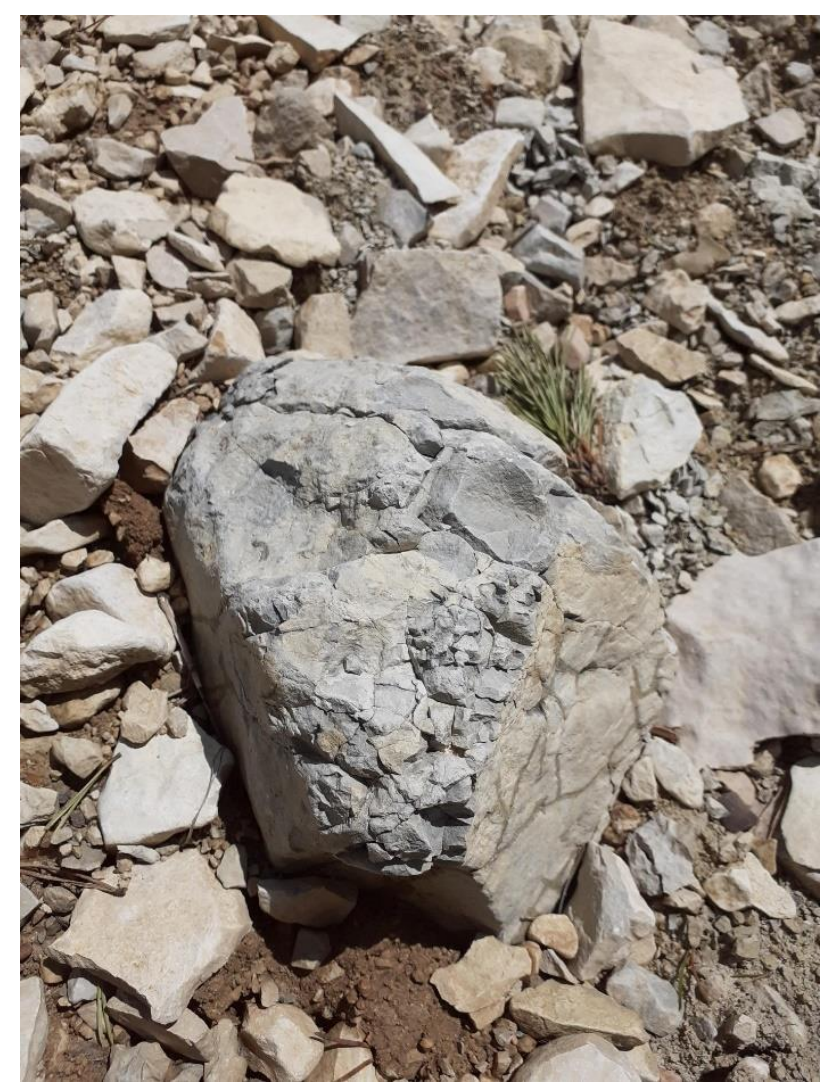

Its lengthy body :

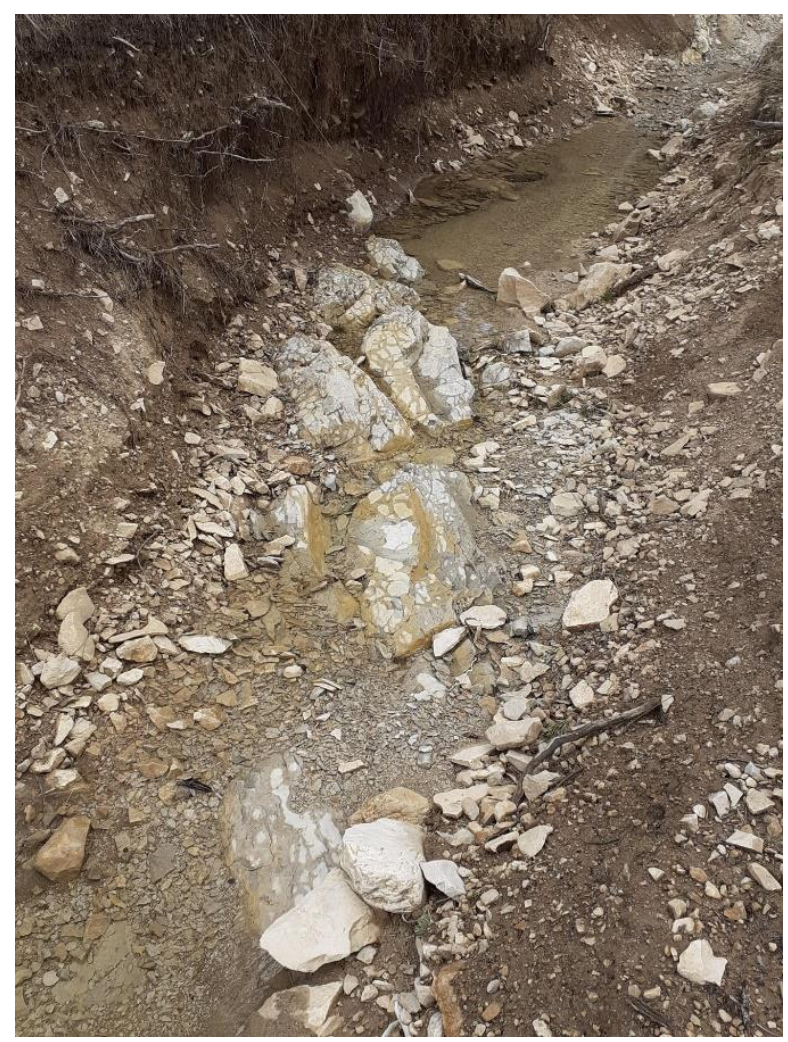


And a baby stegosaurus behind with the head to the right near the shadow and the back emerging (whiter stones as the young animal had no internal contamination with alpha emitters and so the remains are mostly carbonates) :

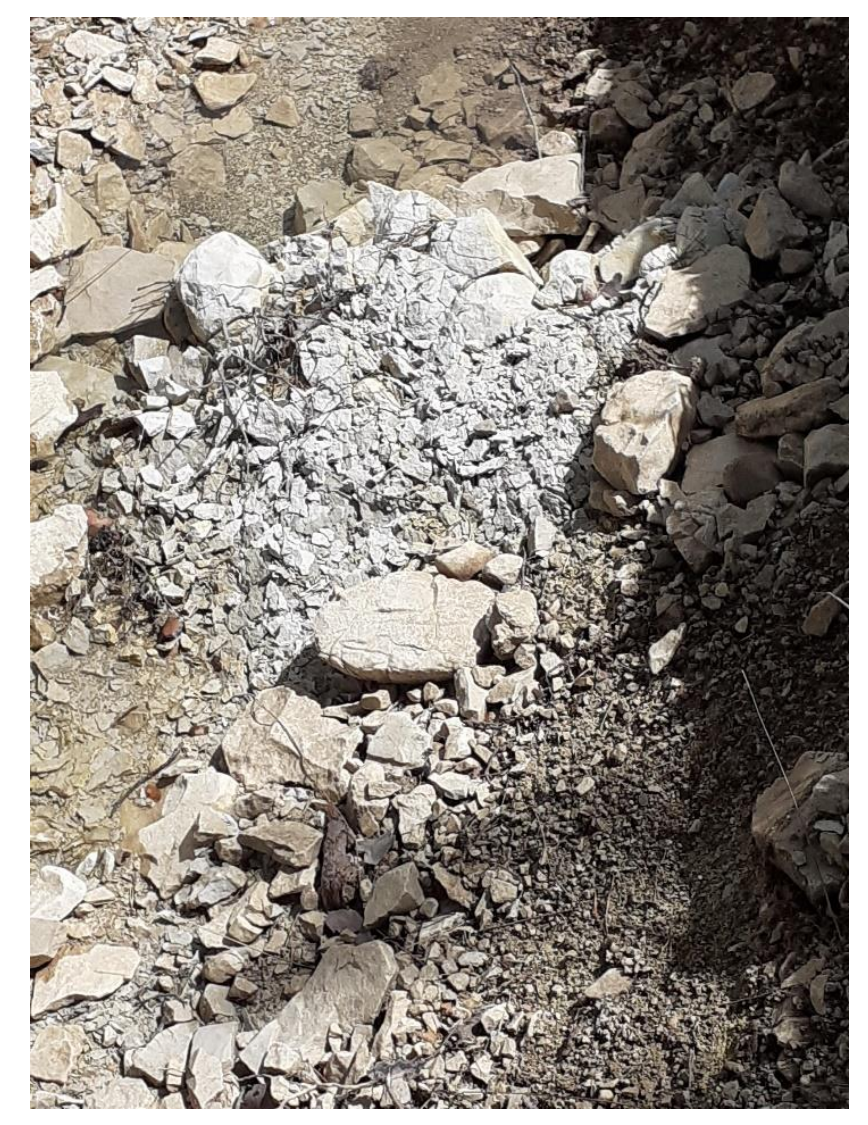

The wealth in fossils of the sector is not entirely displayed in the above cases that show exceptional findings of the author over a month of study and more is obviously still to be found.

\section{Archaeological juxtaposition :}

It is difficult to undertake paleontology in the French Riviera without taking into account more recent remains. In around $451 \mathrm{AD}$, just after the Catalaunian Plains battle, some Huns are known to have taken the direction of the "Julian Alps" and have besieged a place known as "Aquileia" after crossing the Julian Alps. A rational rereading of an historical corpus where quidproquos because of the antiquity of the texts (by authors who may also have missed some important information or were maybe willing to rewrite in ways that allowed to hide humiliating details...) can create gaps in understanding directs the eyes to the shortest path, along the Préalpes grassoises north of which sit a village known today as St Julien du Verdon, from a Catholic saint living in these times, and the sack of Aquileia is shown to be the sack of a village known today as Aiglun, also in this path in the direction of Italy. The Huns established their camp in a flat surrounded by small mountaineous hills, left empty today except for a small farm on a side, Le Pali. Pali is also the name of the Buddhist scripture, the East Asian tradition Huns descended from. The magmatism of the Alps was then active with some lava lakes, because of the pressure from the many groups around, Vandals certainly having accumulated lots of pillaged gold, weighing on the crust ${ }^{[4]}$ and perhaps because of some stellar event in addition to that. The Huns eliminated the Vandals by throwing them into a lava lake. The closure gave to Vescous its name ("closed", "sewed vase »). The flag of Nice with its red eagle implicitly designates as well the event. The shapes of the skulls and of some weapons 
Florent Pirot, IJAHR 2021, 2:7

(including very typical «umbo » shields, and swords) are visible in the lava flows around. The explosions in the magma chamber from that intake of organic matter created shockwaves that carried around the shapes of the skulls, and on several valleys the outer layers of rocks have received scissoring degradations that cause the emergence of face forms. The most typical being the "tête de femme" in the Daluis whose femininity is very dubious. The long valley harmonized the waves from the explosions of the magmatic chamber near Aiglun, and its multiple skulls, into a single general skull shape that is necessarily an aggregation of the most dense parts of all skulls ; that shape came onto a peripheral lava block and was carved onto it progressively.

The skulls still into the magmatic chamber can even be seen from above when a thin veil of clouds combines with the magmatism triggered by heat and economic pressure. A few days ago :
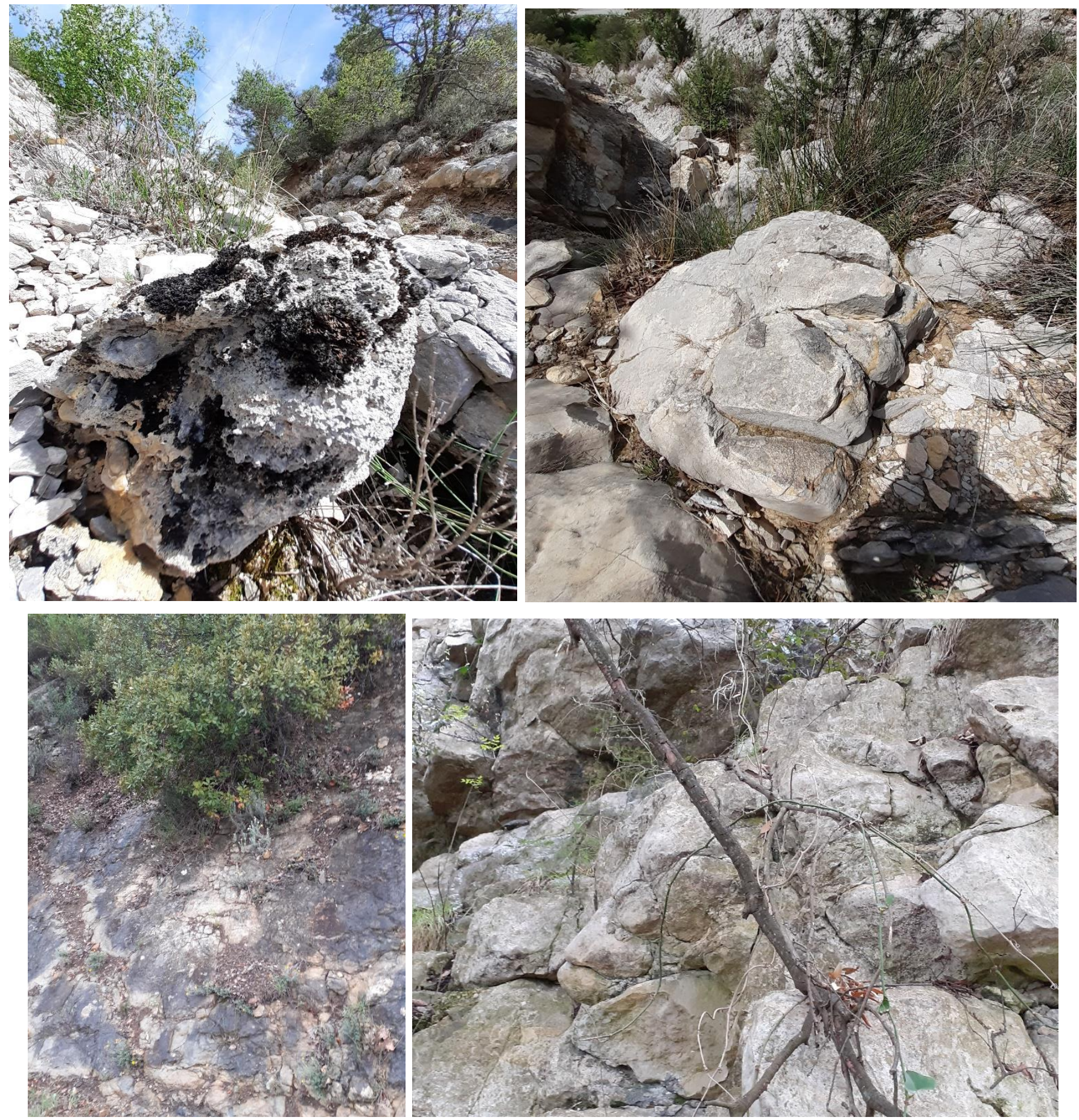
These pictures show a Vandal holding an Umbo shield with his left hand, right hand raised as he fell into the liquid lava in the fight. The very liquid lava kept perfectly his shape in the ulterior spill below the crater. See also for reference ${ }^{[5]}$. One can see that the umbo shield had a head on its right side and another scarier head (bull-like) in the middle looking right at the enemy. Another scarier head (bull or hog-like) in the middle looking right at the enemy. The umbo was certainly carved after the Christian ichthys ("Jesus fish") with the mouth of the central head for the Theta, that coincidentally represents God - hence the choice of a particularly scary head. The Vandals had clearly converted to Christianity unlike the Huns. The semicircular umbo edge can be seen above emerging thinly.
There obviously was a third head popping out on the left side of the umbo that is not visible. The hand was holding it inside. This umbo appears more clearly as shockwaves from the magmatic blasts, benefitting from neutron moderation allowed by the men's bodies, also carried southwards the shapes, printed down by concussion on more ductile rocks - the emerged result with the umbo more clearly visible was found high on the south of the Gorges du Loup, the shape of the face seems to be identical to the Tête de Femme, in both cases valleys acted as tunnels transmitting and concentrating very well the waves produced by the neutron moderation differences in the magma chamber - almost like natural tunnel microscopes."
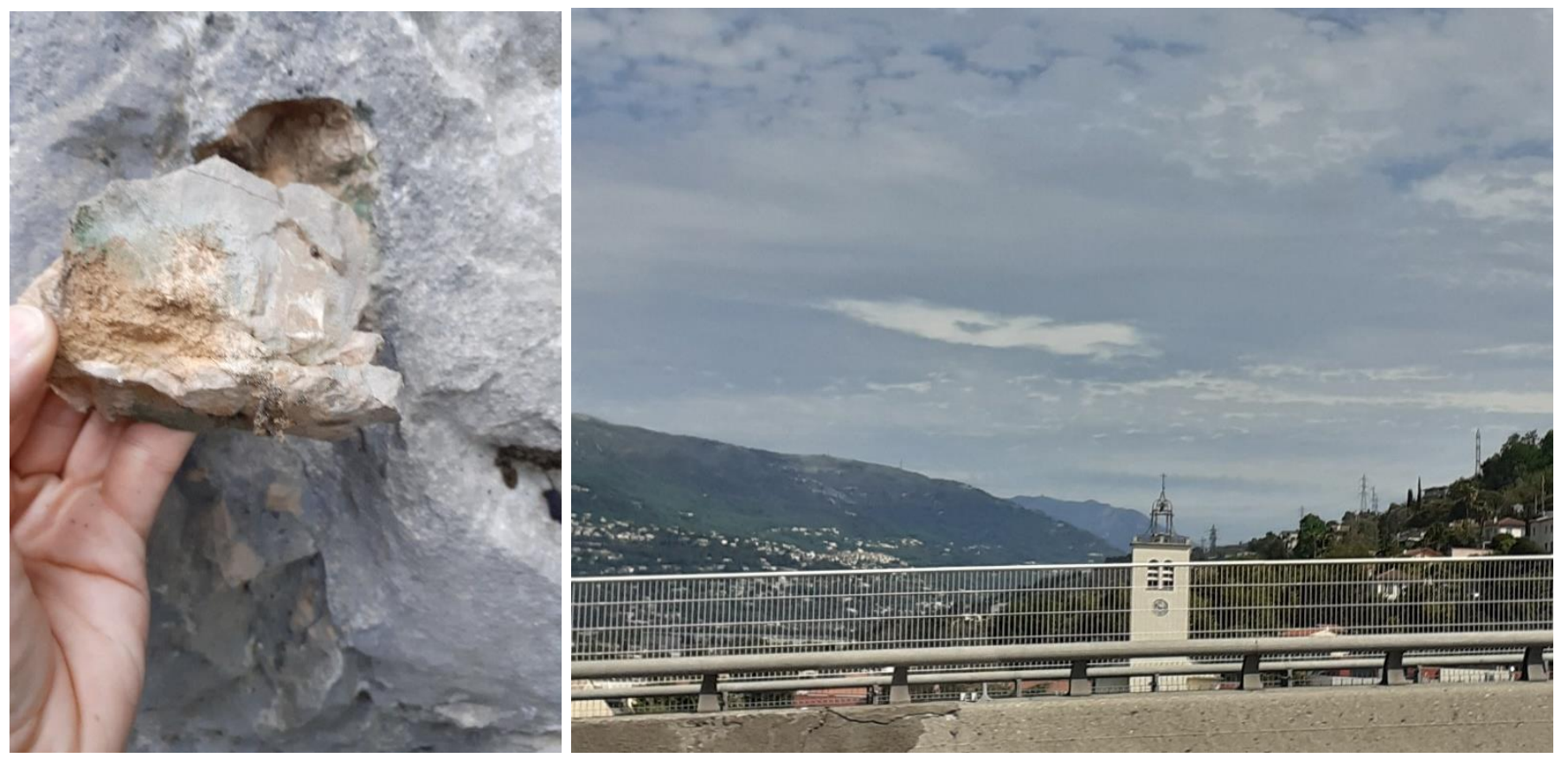

The permanent effect of the still existing skulls and bones in the magmatism was evidenced when pinching the rocks right under the carved aftershock locates high above the Gorges du Loup behind Gourdon, another skull shape was immediately collected. The fish umbo Vandal was certainly the very last victim of the sack. Many other victims accumulated under him were molten into the lava more thoroughly but the shapes of their remains are also propagated through the same processes - that skull was collected one meter only below the Vandal pictured before (below and to his right, opposite of the umbo). It's a still ongoing movement of slow skeleton shape transfer through the local magmatic-seismic activity, that has to be definitively isolated from the paleontological study of sites that frequently meet and juxtapose onto each other, making sometimes difficult the conclusion. 


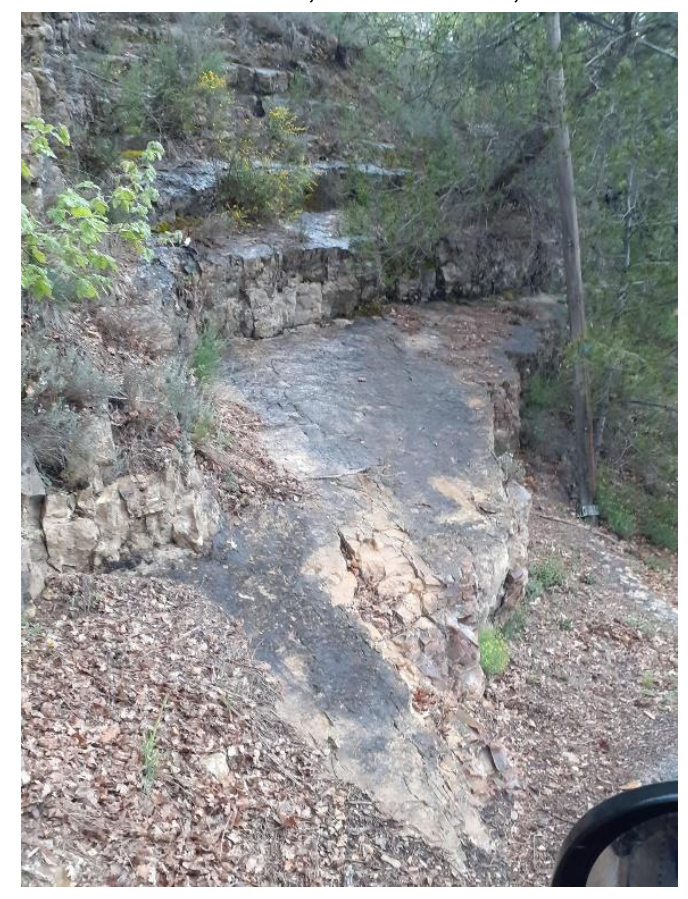

Lastly, skulls from the 1612 AD eruption that happened under a village in the Valdeblore area also emerge in magma blocks that show gold inclusions. A small group of stealers had established its wealth repository in a high altitude village in the area now known as the Millefonds. After the 1604 supernova, the weight from their treasure stimulated magmatism and they ended up in the lava, in a classical case of natural justice.

This final case is a Vandal cranium erupted by the volcano after the Hun killed them. This skull shows the proeminent jaw of a Vandal (they usually wore beards) and the anneal of the helmet is obvious above the eyes, as the Vandal was thrown obviously in the lava in his full battle gear. The paucity of crystallization again confirms it was a limited time stay in the magma chamber after throwing by the Huns in the event obviously commemorated with the red eagle flag of Nice. This skull was found just near the allosaurus and triceratops presented in the introduction, demonstrating again the hardships of the archaeologist to avoid invention of chimera animals and dinosaur humans.

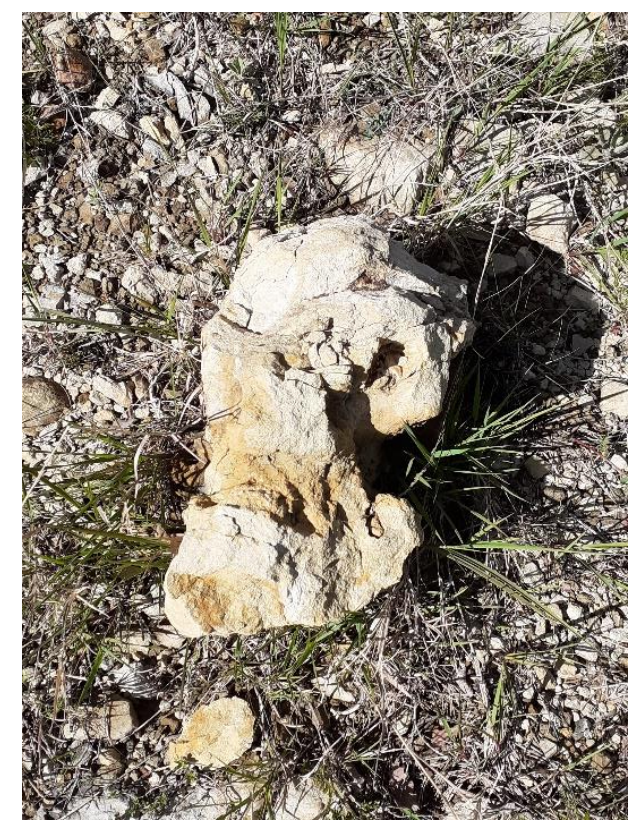



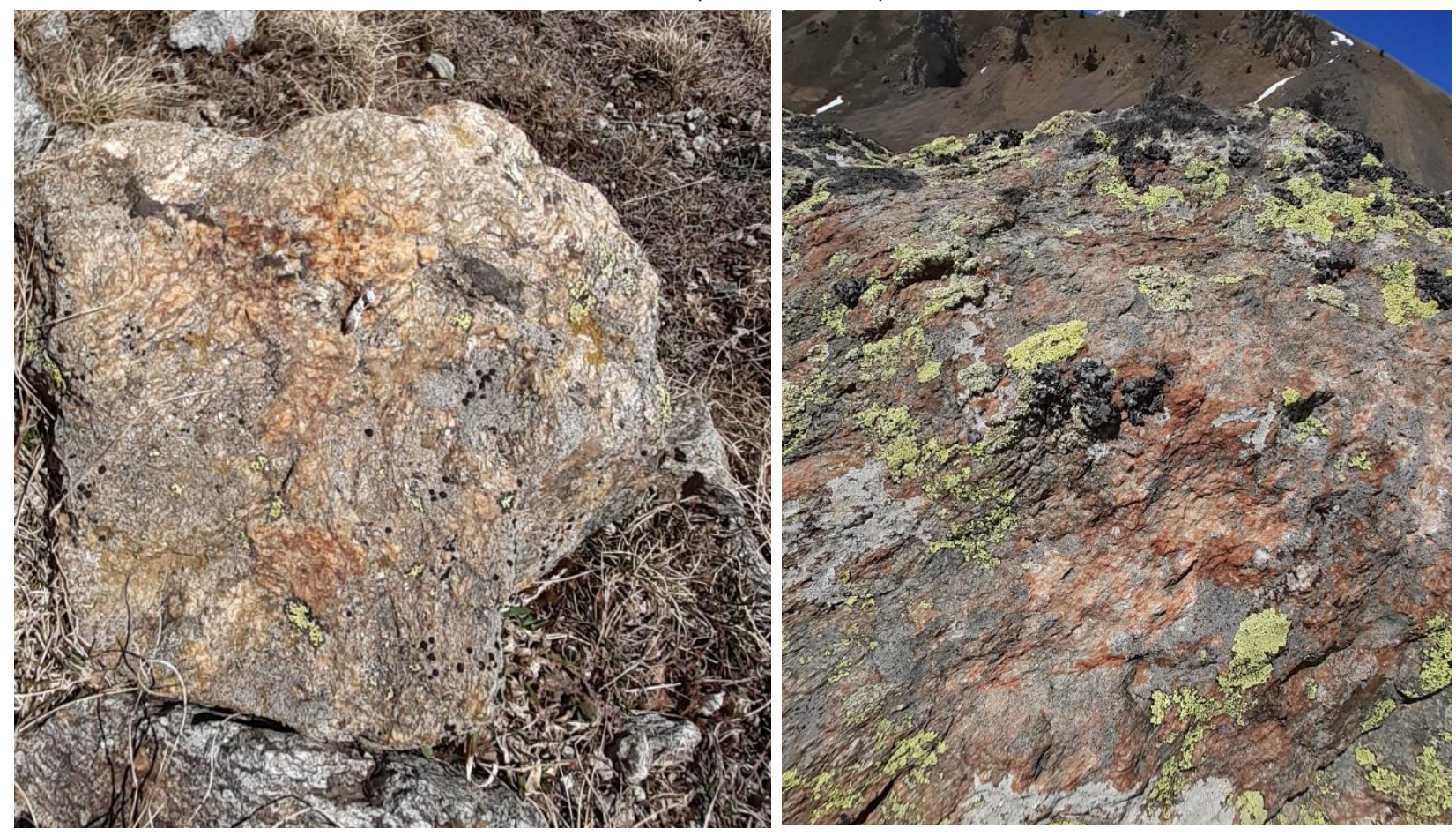

\section{References:}

[1]. Pirot F, Fermionic Condensation Explains the Formation of Subcontinents and Small Volcanic Islands around Them - General Geophysical Rules. International Journal of Physics. 2021; 9(1):42-47. doi: 10.12691/ijp-9-1-5

[2]. Pirot F, Contamination with Natural Radioactivity and Other Sources of Energy - the Explanation for Bose-Einstein Condensates, for the Creeping Behaviour of Helium and for the "Casimir Effect", International Journal of Physics. 2019, 7(3), 95-96. doi: 10.12691/ijp-7-3-5

[3]. Pirot F, Alpha-Emitting Nanoparticulates and Their Various Physical Effects: More Case Studies in Laboratory Research and History, Applied Mathematics and Physics, 2020, 8(1), 1-7. DOI: 10.12691/amp-8-1-1

[4]. Pirot F. A Rule of Natural Disasters Coming to Rebalance Unjust Development and Irresponsibility-Laws of Physics Explain the Trope of "Divine Retribution" against the "Nouveaux Riches". International Journal of Physics. 2019; 7(4):135-140. doi: 10.12691/ijp-7-4-4

[5]. Pirot, F. General Physics of "mystical Face apparitions": Why People Come to Believe in Hypothetical "Virgin Mary or Jesus faces". EJAS 2021, 9, 94-96. 